\title{
Führungswechsel bei FMH Services
}

\section{Max Giger ${ }^{a}$, Sven Bradke ${ }^{b}$}

a Dr. med., Präsident FMH Services

b Dr. rer. publ. HSG, Vizepräsident FMH Services
Geschätzte Kunden, Partner und Genossenschafter

Wir informieren Sie heute über den geplanten Führungswechsel in der Genossenschaft FMH Services sowie über die Änderung der Geschäftsführung bei unserer Tochterunternehmung, der FMH Consulting Services AG.

Reinhard Kunz wird nach sieben Jahren die Geschäftsführung der FMH Services abgeben und im April 2012 in den Ruhestand treten. Unter seiner Führung positionierten sich die FMH Services als eine erfolgreiche und anerkannte Beratungsunternehmung. Wir danken Reinhard Kunz schon heute für die engagierte, kompetente und erfolgreiche Führung unserer Organisation.

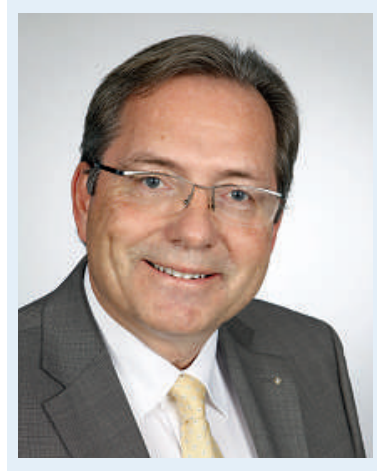

Beat Bär wird ab Februar 2012 die Führung der FMH Services übernehmen. internationalen Dienstleistungsorganisationen mit Schwerpunkt Versicherung tätig. Wichtige Stationen seiner beruflichen Laufbahn waren:

Verantwortung für das Personenversicherungsgeschäft und später Regionaldirektion Bern/Mittelland der ELVIA Versicherung (Allianz Suisse); Leiter der Direktion Bern und Mitglied der Geschäftsleitung Zurich Schweiz, später Leiter KMU-Geschäft und schliesslich Verantwortlicher für die Marktorganisation der Zurich Schweiz; Projektverantwortung für den internationalen Agenturvertrieb von Zurich Financial Services.

Beat Bär hat federführend in der Entwicklung unseres innovativen und modularen Beratungsmodells für die Praxisberatung «GP Box» mitgearbeitet. Er wird sich auch weiterhin intensiv dieser Fragestellung widmen.

René Häller, Betriebsökonom HWV/FH, geb. 1970, übernimmt ab 1. Dezember 2011 die alleinige Führung unserer Tochterunternehmung FMH Consulting Services AG, deren Entwicklung er in den vergangenen fünfzehn Jahren massgebend mitgeprägt hat.

Das Jahr 2011 werden wir als ein weiteres, erfolgreiches Geschäftsjahr abschliessen. In den kommenden Jahren werden wir uns verstärkt in der Beratung der Praxisgestaltung und Praxisführung engagieren und so die Ärzteschaft in den unternehmerischen Veränderungen des Gesundheitswesens unterstützen. Die Mitglieder der Verwaltung
Korrespondenz: FMH Services

Burghöhe 1

Postfach 246

CH-6208 Oberkirch

beat.baer[at]fmhconsulting.ch

\section{«In den kommenden Jahren werden wir uns verstärkt in der Beratung der Praxisgestaltung und Praxisführung engagieren und so die Ärzteschaft in den unternehmerischen Veränderungen des Gesundheitswesens unterstützen.»}

Beat Bär, lic. oec. HSG, geb. 1953, wird ab 1. Februar 2012 die Führung der FMH Services übernehmen.

Wir freuen uns, dass wir mit Beat Bär einen kompetenten und erfahrenen Nachfolger für Reinhard Kunz gefunden haben. Beat Bär war bisher als Führungskraft in verschiedenen schweizerischen und und des Verwaltungsrates freuen sich auf diese Herausforderungen und insbesondere auf die $\mathrm{Zu}$ sammenarbeit mit der erfahrenen Führungscrew. Wir sind überzeugt, die erfolgreiche Entwicklung unserer Unternehmen weiter vorantreiben $\mathrm{zu}$ können. 